\title{
ВИЗНАЧЕННЯ ФІЗИКО-МЕХАНІЧНИХ ВЛАСТИВОСТЕЙ ДОРОЖНІХ БІТУМІВ, МОДИФІКОВАНИХ ЕПОКСИДОМ СОНЯШНИКОВої ОЛІї
}

\author{
DETERMINATION OF PHYSICAL AND MECHANICAL PROPERTIES \\ OF ROAD BITUMINS MODIFIED BY SUNFLOWER OIL EPOXY
}

Шимчук О.П., к.т.н., доц., Талах Л.О., к.т.н., доц., Андрійчук О.В., к.т.н., доц., Процюк В.О., к.т.н., асистент (Луцький національний технічний університет)

Shymchuk O.P., Ph.D. in Engineering, Associate Professor, Talakh L.O Ph.D. in Engineering, Associate Professor, Andriichuk O.V., Ph.D. in Engineering, Associate Professor, Protsiuk V.A. Ph.D. in assistant of Highways and Airfields (Lutsk National Technical University)

Анотація. Експериментально доведено, щуо модифікація дорожніх бітумів 3 допомогою епоксиду соняшникової олї веде до зміни фізико-механічних властивостей модифікованого бітуму, таких як: пенетрація, температура розм'якшення, дуктильність, температура крихкості.

Summary. Development of the national economy and raising the level of economy of our country is impossible without the development of a modern road network. Roads are constantly under load and are exposed to atmospheric phenomena, they wear out. To a large extent, the quality of the roads depends on the roadwear and the materials it consists of. Therefore, in many countries of the world, considerable attention is paid to the proper selection of materials for structural layers of road clothing. Particular attention should be paid to bitumen, which is part of asphalt concrete. Today, the problem of improving the quality of road bitumen, which solution will allow to extend the life of road asphalt pavements and to increase the efficiency of works on their construction and repair, is especially urgent.

It is possible to solve the problem of improving the quality of bitumen by the use of various additives for its modification. An effective way to improve the quality of pavements is to use bitumen modified with epoxy compounds, especially on the basis of reducing raw materials, such as vegetable oils.

For the experimental part of the work used road oil bitumen brand BND 90/130 and BND 60/90, as well as sunflower oil epoxide obtained by epoxidizing it in a medium of hydrogen peroxide.

As a result of the study of road bitumen modified with sunflower oil epoxy, the influence of this additive in different percentages on the structure and properties of bitumen was established. In particular, it has been studied that increasing the content of sunflower oil epoxide in bitumen by more than $7 \%$ is impractical, since virtually no changes such as penetration, softening temperature, ductility and brittleness are observed. 
The results obtained prove that the introduction of sunflower oil epoxide into the bitumen, regardless of its brand, allows to increase the softening temperature by $3-5{ }^{\circ} \mathrm{C}$. The ductility and brittleness are practically equal to the ductility and brittleness of unmodified bitumen. Penetration of modified bitumen is significantly reduced.

Based on the above, it can be argued that the modification of road bitumen with sunflower oil epoxy makes it possible to improve the road performance regardless of the brand of bitumen.

Ключові слова: бітум, модифікація, епоксид, пенетраиія, температура розм'якшення, дуктильність, температура крихкості.

Keywords: bitumen, modification, epoxide, penetration, softening temperature, ductility, brittleness.

Постановка проблеми. Розвиток народного господарства та підвищення рівня економіки нашої держави неможливі без розвинутої сучасної мережі автомобільних доріг.

В значній мірі якість автомобільних доріг залежить від дорожнього одягу та матеріалів, з яких він складається. Конструкція дорожнього одягу $\epsilon$ одним із найвідповідальніших елементів автомобільної дороги, що дає можливість виконувати іiі основні функції із забезпечення безперервного, безпечного та зручного руху транспортних засобів при перевезенні вантажів та пасажирів. Тому в багатьох країнах світу приділяється значна увага належному вибору матеріалів для конструктивних шарів дорожнього одягу.

Значну увагу слід приділити бітуму, який входить до складу асфальтобетону. Сьогодні особливо актуальною $є$ проблема підвищення якості дорожніх бітумів, вирішення якої дасть змогу продовжити термін служби дорожніх асфальтобетонних покриттів і підвищити ефективність робіт з їхнього будівництва й ремонту.

За своїми природними властивостями бітум не може повністю задовольнити вимоги, що висуває до нього робота покриттів під дією сучасних транспортних навантажень в сукупності 3 несприятливими погодними умовами.

В Україні гостро стоїть питання щодо підвищення якості бітумів, оскільки вони за своїми властивостями не відповідають нормативним документам та стандартам. Це спричинено відсутністю однорідної сировини для їх виробництва, застарілого обладнання, постійних порушень норм технологічного процесу.

Вирішити проблему покращення якості бітумів можливо завдяки застосуванню різноманітних добавок для його модифікації. Ефективним способом підвищення якості дорожніх покриттів вважається застосування бітумів, модифікованих епоксидними сполуками, особливо на основі відновлювальної сировини, наприклад, рослинних олій $[1,2]$. 
Модифікація дорожніх бітумів епоксидом соняшникової олії дозволяє покращити експлуатаційні характеристики дорожніх покриттів, причому залежно від вмісту добавки і способу їі введення можна отримати бітуми 3 різними властивостями. Асфальтобетон, виготовлений на основі бітумів, модифікованих епоксидною соняшниковою олією, має вищі показники міцності, водостійкості, порівняно з іншими асфальтобетонами. В цьому випадку знижуються динамічні дії на нижні шари і зменшується можливість копіювання тріщин та інших дефектів шарів, що перекриваються.

Аналіз відомих досліджень. Можливість використання модифікованих бітумів різними сполуками, в тому числі, епоксидними, в дорожньому будівництві вивчали науковці як в Україні, так і за кордоном $[1,2,3]$. Проте питанням добавки до бітуму епоксиду соняшникової олії в якості модифікатора дослідники уваги не приділяли.

Метою роботи було дослідження впливу епоксиду соняшникової олії на структуру і властивості бітумів, який забезпечить покращення фізикомеханічних характеристик цих матеріалів шляхом модифікації.

Результати досліджень. Для проведення експериментальної частини роботи використовували дорожній нафтовий бітум марки БНД 90/130 та БНД 60/90, а також епоксид соняшникової олії, одержаний шляхом епоксидування ії в середовищі пероксиду водню.

До показників, які характеризують властивості твердих бітумів, відносяться глибина проникнення стандартної голки (пенетрація), температура розм'якшення, розтяжність (дуктильність), температура крихкості.

Пенетрація - показник, що характеризує глибину проникнення тіла стандартної форми в напіврідкі і напівтверді продукти при певному режимі, що обумовлює здатність цього тіла проникати в продукт, а продукту - чинити опір цьому проникненню. Пенетрацію визначають за методикою, поданою в [4]; за одиницю пенетрації прийнята глибина проникнення голки на 0,1 мм.

Температура розм'якшення бітумів - це температура, при якій бітуми 3 відносно твердого стану переходять в рідкий. Методика визначення температури розм'якшення умовна і науково не обгрунтована, але широко застосовується на практиці. Випробування проводили за методикою [5] методом «кільце і куля».

Розтяжність (дуктильність) бітуму характеризується відстанню, на яку його можна витягнути в нитку до розриву. Цей показник побічно характеризує також прилипаємість бітуму і пов'язаний з природою його компонентів. Дорожні нафтові бітуми мають високу розтяжність - більше 40 см. Підвищення розтяжності бітумів не завжди відповідає поліпшенню їх властивостей. Розтяжність бітумів при $25^{\circ} \mathrm{C}$ має максимальне значення, яке відповідає їх переходу від стану ньютонівської рідини до 
структурованої. Чим більше бітум відхиляється від ньютонівського течії, тим менше його розтяжність при $25^{\circ} \mathrm{C}$, але досить висока при $0{ }^{\circ} \mathrm{C}$. Бітум повинен мати підвищену розтяжність при низьких температурах $\left(0\right.$ i $\left.15{ }^{\circ} \mathrm{C}\right)$ і помірну - при $25^{\circ} \mathrm{C}$. Випробування проводили за методикою [6].

Температура крихкості - це температура, при якій матеріал руйнується під дією короткочасно прикладеного навантаження. За Фраасом - це температура, при якій модуль пружності бітуму при тривалості навантаження $11 \mathrm{c}$ для всіх бітумів однаковий і рівний 1100 кг/см2 (1,0787-108 H/m²). Температура крихкості характеризує поведінку бітуму в дорожньому покритті: чим вона нижча, тим вища якість дорожнього бітуму. Окислені бітуми мають нижчу температуру крихкості, ніж інші бітуми тієї ж пенетрації. Випробування проводили за методикою [7].

В результаті дослідження дорожніх бітумів, модифікованих епоксидом соняшникової олії, встановлено вплив даної добавки в різному відсотковому співвідношенні на структуру і властивості бітумів. Зокрема вивчено, що збільшення вмісту епоксиду соняшникової олії в бітумі понад 7\% є недоцільним, оскільки практично не змінюються такі показники, як пенетрація, температура розм'якшення, дуктильність і температура крихкості.

Результати досліджень дорожніх бітумів, модифікованих епоксидом соняшникової олії, наведені в таблицях 1 та 2 та рисунках 1, 2, 3, 4, 5 та 6.

Таблиця 1

Результати випробувань бітуму БНД 90/130 з добавками епоксиду соняшникової олії 2\%, 3\%, 5\% та 7\% від маси бітуму

\begin{tabular}{|c|c|c|c|c|c|}
\hline Назва показника & $\begin{array}{l}\text { БНД } \\
90 / 130\end{array}$ & $\begin{array}{l}\text { БНД } \\
90 / 130 \\
+2 \% \\
\text { ECO }\end{array}$ & $\begin{array}{l}\text { БНД } \\
90 / 130 \\
+3 \% \\
\text { ECO }\end{array}$ & $\begin{array}{l}\text { БНД } \\
90 / 130 \\
+5 \% \\
\text { ЕСО }\end{array}$ & $\begin{array}{l}\text { БНД } \\
90 / 130 \\
+7 \% \\
\text { ЕСО }\end{array}$ \\
\hline $\begin{array}{l}\text { 1. Глибина проникнення голки } \\
\text { (пенетрація), } 0,1 \mathrm{mм} \\
\text { за температури } 25^{\circ} \mathrm{C} \\
\text { за температури } 0{ }^{\circ} \mathrm{C}\end{array}$ & $\begin{array}{l}102 \\
25\end{array}$ & $\begin{array}{l}99 \\
23\end{array}$ & $\begin{array}{l}87 \\
24\end{array}$ & $\begin{array}{l}59 \\
21\end{array}$ & $\begin{array}{l}57 \\
22\end{array}$ \\
\hline $\begin{array}{l}\text { 2. Температура розм’якшення за } \\
\text { кільцем та кулею, }{ }^{\circ} \mathrm{C}\end{array}$ & 46 & 51 & 51 & 53 & 53 \\
\hline $\begin{array}{l}\text { 3. Розтяжність (дуктильність), см: } \\
\text { за температури } 0{ }^{\circ} \mathrm{C} \\
\text { за температури } 25^{\circ} \mathrm{C}\end{array}$ & $\begin{array}{l}5,0 \\
91\end{array}$ & $\begin{array}{l}5,0 \\
88\end{array}$ & $\begin{array}{l}5,1 \\
87\end{array}$ & $\begin{array}{l}5,3 \\
83\end{array}$ & $\begin{array}{l}5,0 \\
85\end{array}$ \\
\hline 6. Температура крихкості, ${ }^{\circ} \mathrm{C}$ & -27 & -27 & -28 & -28 & -26 \\
\hline
\end{tabular}

Результати проведених досліджень показали, що введення епоксиду соняшникової олії в дорожній бітум зменшує пенетрацію та підвищує 
температуру розм'якшення, а на розтяжність і температуру крихкості має незначний вплив.

Таблиця 2

Результати випробувань бітуму БНД 60/90 з добавками епоксиду соняшникової олії 2\%, 3\%, 5\% та 7\% від маси бітуму

\begin{tabular}{|c|c|c|c|c|c|}
\hline Назва показника & $\begin{array}{l}\text { БНД } \\
60 / 90\end{array}$ & $\begin{array}{l}\text { БНД } \\
60 / 90 \\
+2 \% \\
\text { ECO }\end{array}$ & $\begin{array}{l}\text { БНД } \\
60 / 90 \\
+3 \% \\
\text { ECO }\end{array}$ & $\begin{array}{l}\text { БНД } \\
60 / 90 \\
+5 \% \\
\text { ECO }\end{array}$ & $\begin{array}{l}\text { БНД } \\
60 / 90 \\
+7 \% \\
\text { ECO }\end{array}$ \\
\hline $\begin{array}{l}\text { 1. Глибина проникнення голки } \\
\text { (пенетрація), } 0,1 \mathrm{mм} \\
\text { за температури } 25^{\circ} \mathrm{C} \\
\text { за температури } 0{ }^{\circ} \mathrm{C}\end{array}$ & $\begin{array}{l}90 \\
16\end{array}$ & $\begin{array}{l}82 \\
15\end{array}$ & $\begin{array}{l}67 \\
16\end{array}$ & $\begin{array}{l}59 \\
18\end{array}$ & $\begin{array}{l}57 \\
22\end{array}$ \\
\hline $\begin{array}{l}\text { 2. Температура розм'якшення за } \\
\text { кільцем та кулею, }{ }^{\circ} \mathrm{C}\end{array}$ & 48 & 50 & 50 & 48 & 44 \\
\hline $\begin{array}{l}\text { 3. Розтяжність (дуктильність), см: } \\
\text { за температури } 0^{\circ} \mathrm{C} \\
\text { за температури } 25^{\circ} \mathrm{C}\end{array}$ & $\begin{array}{l}5,0 \\
90\end{array}$ & $\begin{array}{l}4,9 \\
88\end{array}$ & $\begin{array}{l}5,0 \\
88\end{array}$ & $\begin{array}{l}4,3 \\
86\end{array}$ & $\begin{array}{l}4,7 \\
87\end{array}$ \\
\hline 6. Температура крихкості, ${ }^{\circ} \mathrm{C}$ & -25 & -25 & -26 & -26 & -26 \\
\hline
\end{tabular}

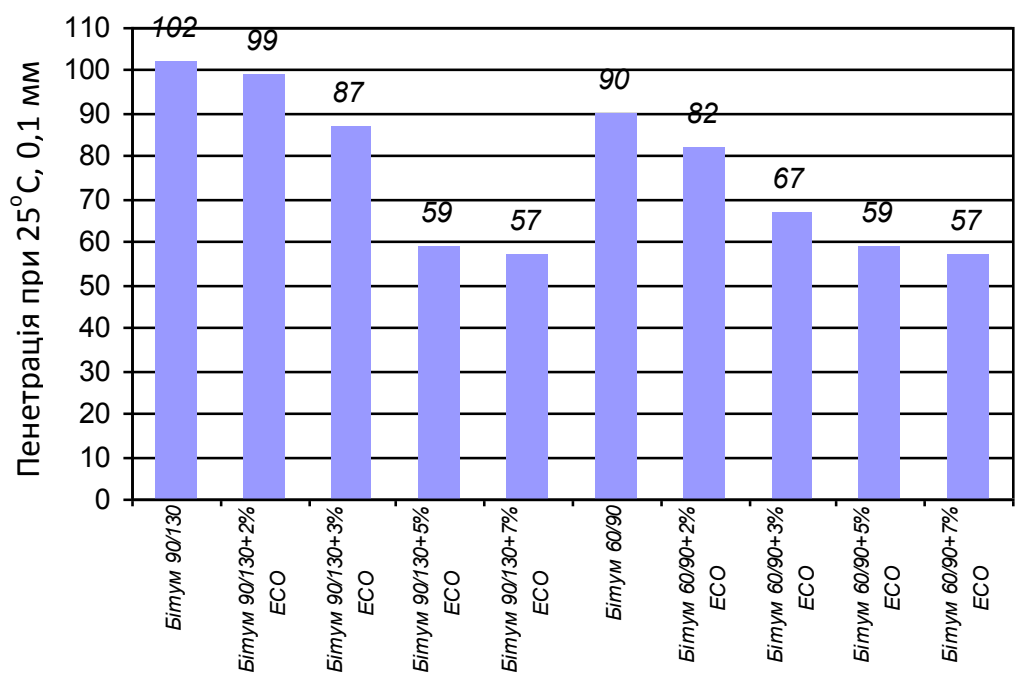

Рис. 1. Пенетрація при $25^{\circ} \mathrm{C}$ вихідного бітуму марки БНД 90/130 та БНД $60 / 90$ та тих же бітумів з добавками ЕСО 2\%, 3\%, 5\% та 7\% від маси бітуму 


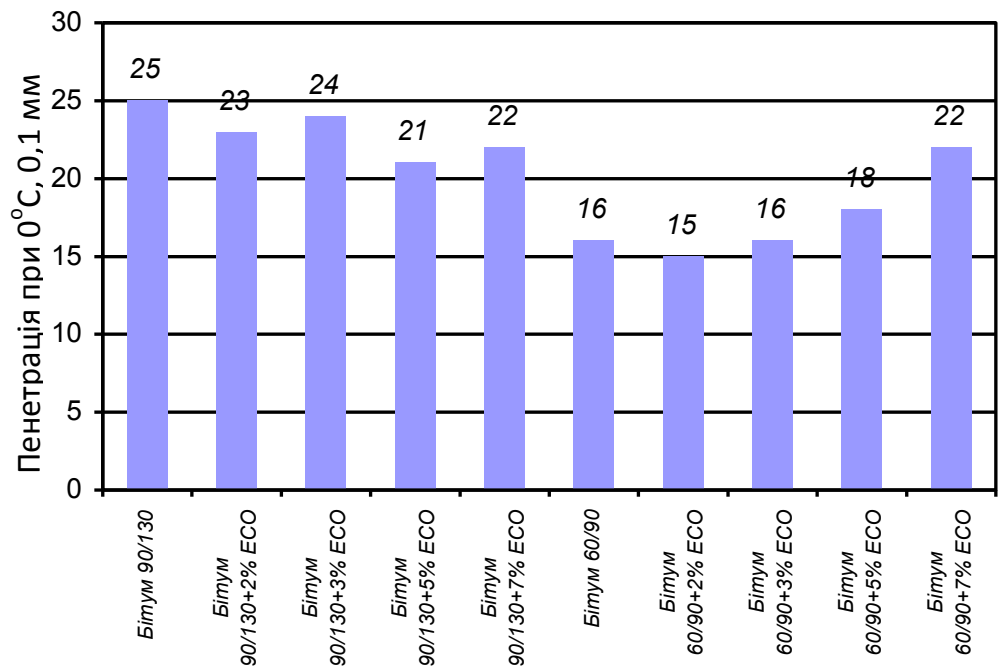

Рис. 2. Пенетрація при $0^{\circ} \mathrm{C}$ вихідного бітуму марки БНД 90/130 та БНД $60 / 90$ та тих же бітумів з добавками ЕСО 2\%, 3\%, 5\% та 7\% від маси бітуму

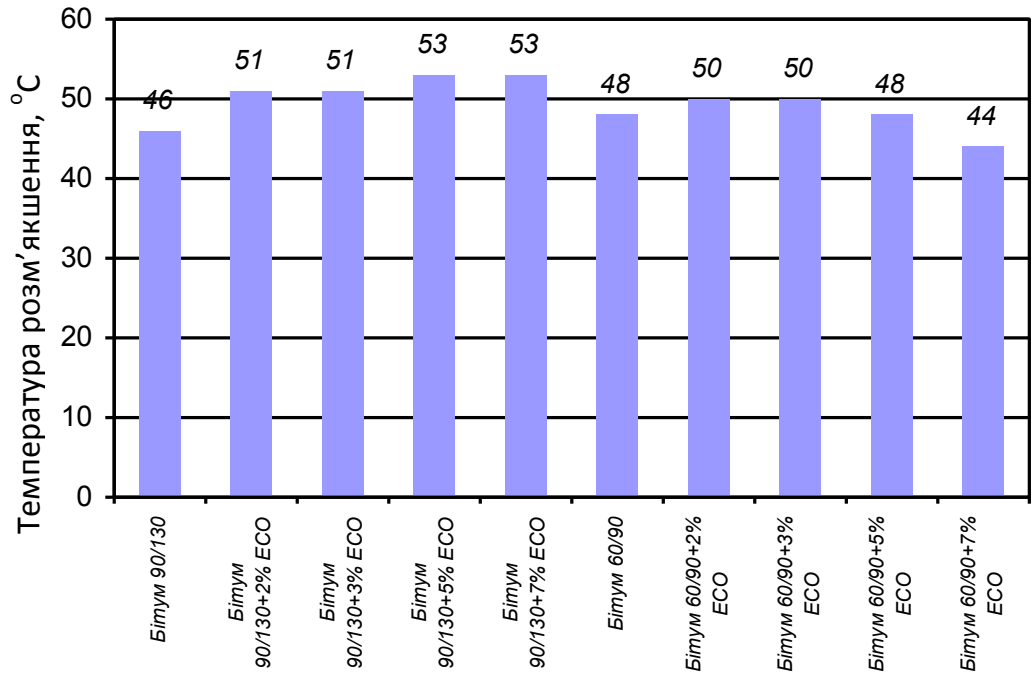

Рис. 3. Температура розм'якшення вихідного бітуму марки БНД 90/130 та БНД 60/90 та тих же бітумів з добавками ЕСО 2\%, 3\%, 5\% та 7\% від маси бітуму 


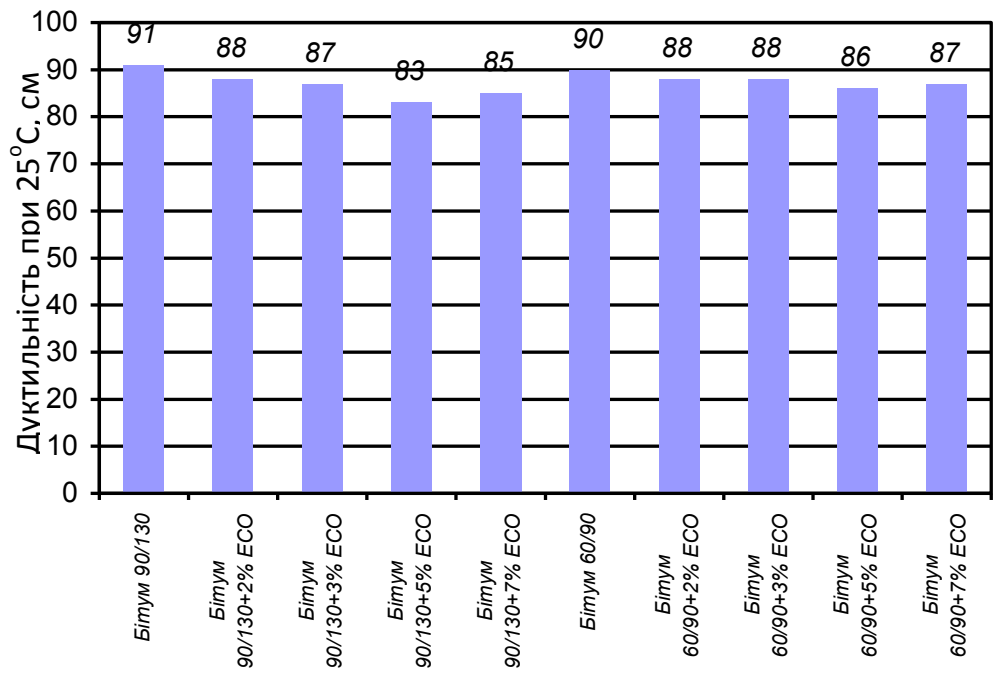

Рис. 4. Дуктильність при $25^{\circ} \mathrm{C}$ вихідного бітуму марки БНД 90/130 та БНД $60 / 90$ та тих же бітумів 3 добавками ЕСО 2\%, 3\%, 5\% та 7\% від маси бітуму

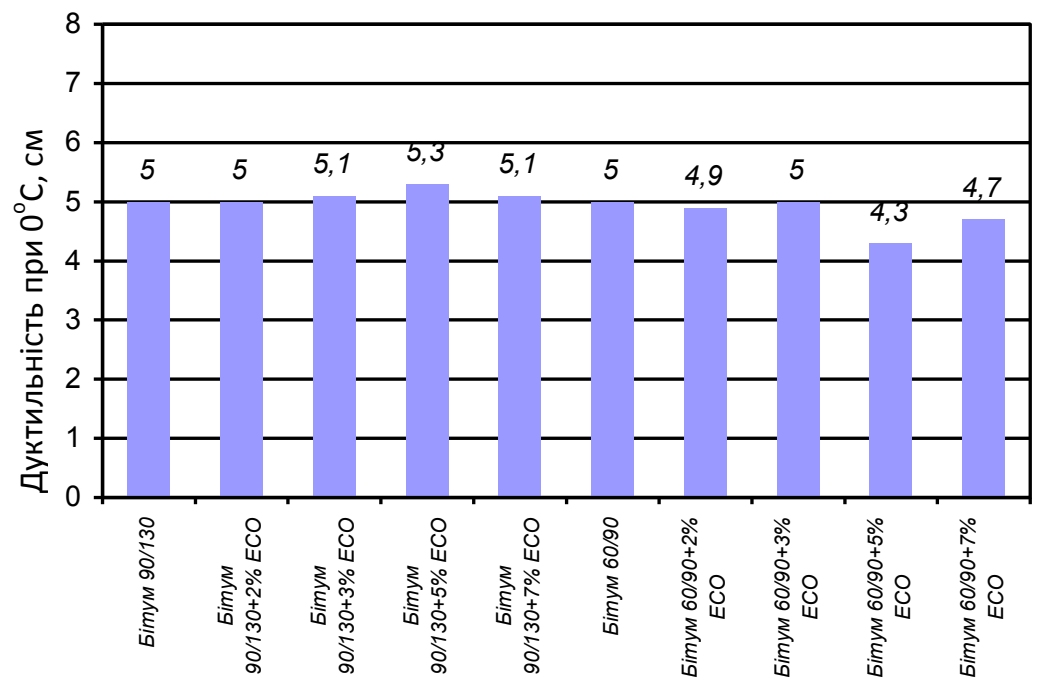

Рис. 5. Дуктильність при $0^{\circ} \mathrm{C}$ вихідного бітуму марки БНД 90/130 та БНД $60 / 90$ та тих же бітумів $з$ добавками ЕСО 2\%, 3\%, 5\% та 7\% від маси бітуму 


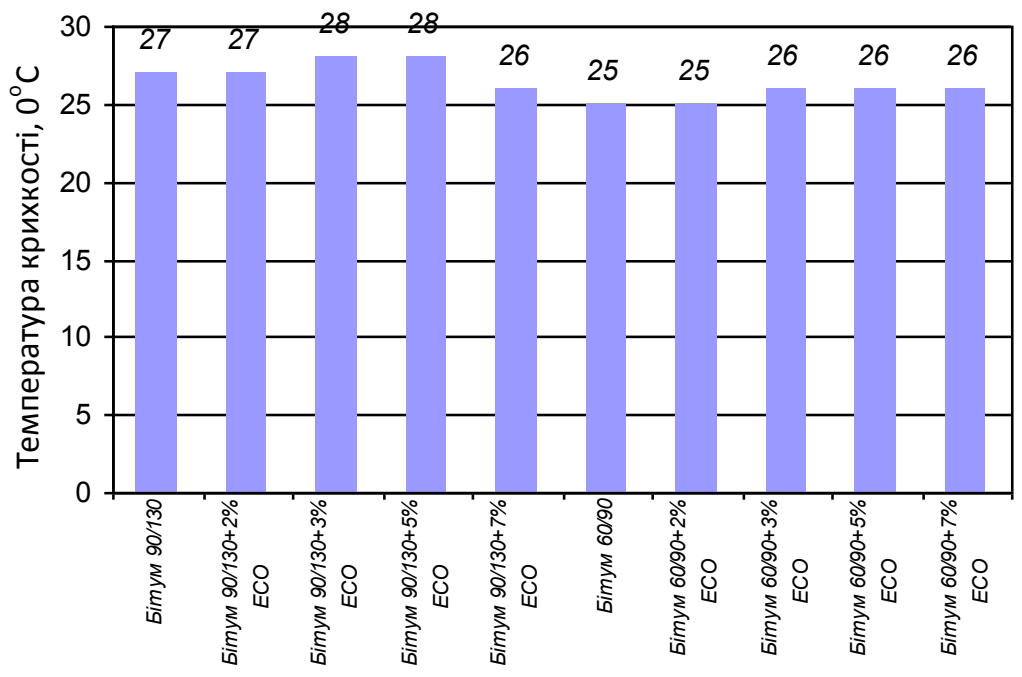

Рис. 6. Температура крихкості вихідного бітуму марки БНД 90/130 та БНД 60/90 та тих же бітумів з добавками ЕСО 2\%, 3\%, 5\% та 7\% від маси бітуму

Висновки. Модифікація дорожніх бітумів 3 допомогою епоксиду соняшникової олії веде до зміни властивостей модифікованого бітуму, таких як: пенетрація, температура розм'якшення, дуктильність, температура крихкості.

Отримані результати дозволяють стверджувати, що введення епоксиду соняшникової олії в бітум, незалежно від його марки, дає змогу підвищити температуру розм'якшення на 3-5 ${ }^{\circ} \mathrm{C}$. Дуктильність та температура крихкості практично $є$ рівною дуктильності та температурі крихкості немодифікованого бітуму.

Пенетрація модифікованих бітумів істотно знижується. Якщо для бітуму марки БНД 60/90 цей показник знижується на 33, порівняно 3 немодифікованим зразком, то для бітуму марки БНД 90/130 зменшення становить 45. Аналізуючи зміни фізико-механічних показників бітумів до і після модифікації, можемо стверджувати, що внаслідок модифікації можлива зміна їх марки.

На основі вищевикладеного можна стверджувати, що модифікація дорожніх бітумів епоксидом соняшникової олії дає змогу покращити експлуатаційні характеристики дорожніх покриттів, незалежно від марки бітуму. 


\section{References}

1. Grinchuk, Yu.M. Epoxy compounds based on rapeseed oil as modifiers for road bitumen [Text] / Grinchuk YM, Nikipanchuk MV // Bulletin of the National University of Lviv Polytechnic. Chemistry, technology of substances and their application. Lviv 2011 - №700. - P. 474-477

2. Grinchuk Yu. Influence of conditions and method of modification of road bitumen with rapeseed oil epoxide on their physicochemical properties / Yu. Grinchuk, MV Nikipanchuk, V.M. Grinchuk // Bulletin of the National university "Lviv Polytechnic". - Ser .: Chemistry, technology of substances and their application. - Lviv: Publishing House of NU "Lviv Polytechnic". - 2013. - № 761. - P. 465-469.

3. Modified bituminous binders, special bitumen and bitumen with additives in road construction / Ed. Zolotaryova VA - Kharkov, 2003. - 28s.

4. GOST 11501-78 Bitumens petroleum. The method of determining the depth of needle penetration.

5. Bitumens are oil. Method of determining the softening temperature by ring and layer (Bitumen oil. Method for determining the softening temperature by ring and ball) GOST 11506-73.

6. GOST 11505-75 Bitumens petroleum. Method of determining stretchability.

7. Bitumens are oil. Method of determining the temperature of brittleness according to Fraas (Bitumen oil. Method of determining the temperature of fragility according to Fraas) - GOST 11507-78.

\section{Список використаної літератури}

1. Гринчук, Ю.М. Епоксидні сполуки на основі ріпакової олії як модифікатори для дорожніх бітумів [Текст] /Гринчук Ю.М., Никипанчук М.В. // Вісник Національного університету “Львівська політехніка". Хімія, технологія речовин та їх застосування. Львів 2011р. - №700. - С. 474-477

2. Гринчук Ю.М. Вплив умов та способу модифікації дорожніх бітумів епоксидом ріпакової олії на їх фізико-хімічні властивості / Ю.М. Гринчук, М.В. Никипанчук, В.М. Гринчук // Вісник Національного університету "Львівська політехніка". - Сер.: Хімія, технологія речовин і їх застосування. - Львів : Вид-во НУ "Львівська політехніка". - 2013. - № 761. - С. 465-469.

3. Модифицированные битумные вяжущие, специальные битумы и битумы с добавками в дорожном строительстве / Под ред. Золотарьова В.А. - Харьков, 2003. $-28 \mathrm{c}$.

4. ГОСТ 11501-78 Битумы нефтяные. Метод определения глубины проникания иглы.

5. Битумы нефтяные. Метод определения температуры размягчения по кольцу и шару (Бітуми нафтові. Метод визначення температури розм'якшеності за кільцем і кулею) - ГОСТ 11506-73.

6. ГОСТ 11505-75 Битумы нефтяные. Метод определения растяжимости.

7. Битумы нефтяные. Метод определения температуры хрупкости по Фраасу (Бітуми нафтові. Метод визначення температури крихкості за Фраасом) - ГОСТ 11507-78. 